\title{
2 \\ ILO Convention No. 169 on Indigenous and Tribal Peoples
}

\section{C169 Indigenous and Tribal Peoples Convention, 1989}

\section{Convention concerning Indigenous and Tribal Peoples in Independent Countries}

The General Conference of the International Labour Organisation,

Having been convened at Geneva by the Governing Body of the International Labour Office, and having met in its 76th Session on 7 June 1989, and

Noting the international standards contained in the Indigenous and Tribal Populations Convention and Recommendation, 1957, and

Recalling the terms of the Universal Declaration of Human Rights, the International Covenant on Economic, Social and Cultural Rights, the International Covenant on Civil and Political Rights, and the many international instruments on the prevention of discrimination, and

Considering that the developments which have taken place in international law since 1957, as well as developments in the situation of indigenous and tribal peoples in all regions of the world, have made it appropriate to adopt new international standards on the subject with a view to removing the assimilationist orientation of the earlier standards, and

Recognising the aspirations of these peoples to exercise control over their own institutions, ways of life and economic development and to maintain and develop their identities, languages and religions, within the framework of the States in which they live, and

Noting that in many parts of the world these peoples are unable to enjoy their fundamental human rights to the same degree as the rest of the population of the States within which they live, and that their laws, values, customs and perspectives have often been eroded, and

Calling attention to the distinctive contributions of indigenous and tribal peoples to the cultural diversity and social and ecological harmony of humankind and to international co-operation and understanding, and 
Noting that the following provisions have been framed with the co-operation of the United Nations, the Food and Agriculture Organisation of the United Nations, the United Nations Educational, Scientific and Cultural Organisation and the World Health Organisation, as well as of the Inter-American Indian Institute, at appropriate levels and in their respective fields, and that it is proposed to continue this cooperation in promoting and securing the application of these provisions, and

Having decided upon the adoption of certain proposals with regard to the partial revision of the Indigenous and Tribal Populations Convention, 1957 (No. 107), which is the fourth item on the agenda of the session, and

Having determined that these proposals shall take the form of an international Convention revising the Indigenous and Tribal Populations Convention, 1957;

adopts the twenty-seventh day of June of the year one thousand nine hundred and eighty-nine, the following Convention, which may be cited as the Indigenous and Tribal Peoples Convention, 1989;

\section{Part I General Policy}

\section{Article 1}

1 This Convention applies to:

(a) tribal peoples in independent countries whose social, cultural and economic conditions distinguish them from other sections of the national community, and whose status is regulated wholly or partially by their own customs or traditions or by special laws or regulations;

(b) peoples in independent countries who are regarded as indigenous on account of their descent from the populations which inhabited the country, or a geographical region to which the country belongs, at the time of conquest or colonisation or the establishment of present state boundaries and who, irrespective of their legal status, retain some or all of their own social, economic, cultural and political institutions.

2 Self-identification as indigenous or tribal shall be regarded as a fundamental criterion for determining the groups to which the provisions of this Convention apply.

3 The use of the term peoples in this Convention shall not be construed as having any implications as regards the rights which may attach to the term under international law.

\section{Article 2}

1 Governments shall have the responsibility for developing, with the participation of the peoples concerned, co-ordinated and systematic action to protect the rights of these peoples and to guarantee respect for their integrity.

2 Such action shall include measures for:

(a) ensuring that members of these peoples benefit on an equal footing from the rights and opportunities which national laws and regulations grant to other members of the population; 


\section{Annexes}

(b) promoting the full realisation of the social, economic and cultural rights of these peoples with respect for their social and cultural identity, their customs and traditions and their institutions;

(c) assisting the members of the peoples concerned to eliminate socio-economic gaps that may exist between indigenous and other members of the national community, in a manner compatible with their aspirations and ways of life.

\section{Article 3}

1 Indigenous and tribal peoples shall enjoy the full measure of human rights and fundamental freedoms without hindrance or discrimination. The provisions of the Convention shall be applied without discrimination to male and female members of these peoples.

2 No form of force or coercion shall be used in violation of the human rights and fundamental freedoms of the peoples concerned, including the rights contained in this Convention.

\section{Article 4}

1 Special measures shall be adopted as appropriate for safeguarding the persons, institutions, property, labour, cultures and environment of the peoples concerned.

2 Such special measures shall not be contrary to the freely-expressed wishes of the peoples concerned.

3 Enjoyment of the general rights of citizenship, without discrimination, shall not be prejudiced in any way by such special measures.

\section{Article 5}

In applying the provisions of this Convention:

(a) the social, cultural, religious and spiritual values and practices of these peoples shall be recognised and protected, and due account shall be taken of the nature of the problems which face them both as groups and as individuals;

(b) the integrity of the values, practices and institutions of these peoples shall be respected;

(c) policies aimed at mitigating the difficulties experienced by these peoples in facing new conditions of life and work shall be adopted, with the participation and co-operation of the peoples affected.

\section{Article 6}

1 In applying the provisions of this Convention, governments shall:

(a) consult the peoples concerned, through appropriate procedures and in particular through their representative institutions, whenever consideration is being given to legislative or administrative measures which may affect them directly;

(b) establish means by which these peoples can freely participate, to at least the same extent as other sectors of the population, at all levels of decisionmaking in elective institutions and administrative and other bodies responsible for policies and programmes which concern them;

(c) establish means for the full development of these peoples' own institutions and initiatives, and in appropriate cases provide the resources necessary for this purpose. 
2 The consultations carried out in application of this Convention shall be undertaken, in good faith and in a form appropriate to the circumstances, with the objective of achieving agreement or consent to the proposed measures.

\section{Article 7}

1 The peoples concerned shall have the right to decide their own priorities for the process of development as it affects their lives, beliefs, institutions and spiritual well-being and the lands they occupy or otherwise use, and to exercise control, to the extent possible, over their own economic, social and cultural development. In addition, they shall participate in the formulation, implementation and evaluation of plans and programmes for national and regional development which may affect them directly.

2 The improvement of the conditions of life and work and levels of health and education of the peoples concerned, with their participation and co-operation, shall be a matter of priority in plans for the overall economic development of areas they inhabit. Special projects for development of the areas in question shall also be so designed as to promote such improvement.

3 Governments shall ensure that, whenever appropriate, studies are carried out, in co-operation with the peoples concerned, to assess the social, spiritual, cultural and environmental impact on them of planned development activities. The results of these studies shall be considered as fundamental criteria for the implementation of these activities.

4 Governments shall take measures, in co-operation with the peoples concerned, to protect and preserve the environment of the territories they inhabit.

\section{Article 8}

1 In applying national laws and regulations to the peoples concerned, due regard shall be had to their customs or customary laws.

2 These peoples shall have the right to retain their own customs and institutions, where these are not incompatible with fundamental rights defined by the national legal system and with internationally recognised human rights. Procedures shall be established, whenever necessary, to resolve conflicts which may arise in the application of this principle.

3 The application of paragraphs 1 and 2 of this Article shall not prevent members of these peoples from exercising the rights granted to all citizens and from assuming the corresponding duties.

\section{Article 9}

1 To the extent compatible with the national legal system and internationally recognised human rights, the methods customarily practised by the peoples concerned for dealing with offences committed by their members shall be respected.

2 The customs of these peoples in regard to penal matters shall be taken into consideration by the authorities and courts dealing with such cases. 


\section{Annexes}

Article 10

1 In imposing penalties laid down by general law on members of these peoples account shall be taken of their economic, social and cultural characteristics.

2 Preference shall be given to methods of punishment other than confinement in prison.

\section{Article 11}

The exaction from members of the peoples concerned of compulsory personal services in any form, whether paid or unpaid, shall be prohibited and punishable by law, except in cases prescribed by law for all citizens.

\section{Article 12}

The peoples concerned shall be safeguarded against the abuse of their rights and shall be able to take legal proceedings, either individually or through their representative bodies, for the effective protection of these rights. Measures shall be taken to ensure that members of these peoples can understand and be understood in legal proceedings, where necessary through the provision of interpretation or by other effective means.

\section{Part II Land}

\section{Article 13}

1 In applying the provisions of this Part of the Convention governments shall respect the special importance for the cultures and spiritual values of the peoples concerned of their relationship with the lands or territories, or both as applicable, which they occupy or otherwise use, and in particular the collective aspects of this relationship.

2 The use of the term lands in Articles 15 and 16 shall include the concept of territories, which covers the total environment of the areas which the peoples concerned occupy or otherwise use.

\section{Article 14}

1 The rights of ownership and possession of the peoples concerned over the lands which they traditionally occupy shall be recognised. In addition, measures shall be taken in appropriate cases to safeguard the right of the peoples concerned to use lands not exclusively occupied by them, but to which they have traditionally had access for their subsistence and traditional activities. Particular attention shall be paid to the situation of nomadic peoples and shifting cultivators in this respect.

2 Governments shall take steps as necessary to identify the lands which the peoples concerned traditionally occupy, and to guarantee effective protection of their rights of ownership and possession.

3 Adequate procedures shall be established within the national legal system to resolve land claims by the peoples concerned. 
Article 15

1 The rights of the peoples concerned to the natural resources pertaining to their lands shall be specially safeguarded. These rights include the right of these peoples to participate in the use, management and conservation of these resources.

2 In cases in which the State retains the ownership of mineral or sub-surface resources or rights to other resources pertaining to lands, governments shall establish or maintain procedures through which they shall consult these peoples, with a view to ascertaining whether and to what degree their interests would be prejudiced, before undertaking or permitting any programmes for the exploration or exploitation of such resources pertaining to their lands. The peoples concerned shall wherever possible participate in the benefits of such activities, and shall receive fair compensation for any damages which they may sustain as a result of such activities.

\section{Article 16}

1 Subject to the following paragraphs of this Article, the peoples concerned shall not be removed from the lands which they occupy.

2 Where the relocation of these peoples is considered necessary as an exceptional measure, such relocation shall take place only with their free and informed consent. Where their consent cannot be obtained, such relocation shall take place only following appropriate procedures established by national laws and regulations, including public inquiries where appropriate, which provide the opportunity for effective representation of the peoples concerned.

3 Whenever possible, these peoples shall have the right to return to their traditional lands, as soon as the grounds for relocation cease to exist.

4 When such return is not possible, as determined by agreement or, in the absence of such agreement, through appropriate procedures, these peoples shall be provided in all possible cases with lands of quality and legal status at least equal to that of the lands previously occupied by them, suitable to provide for their present needs and future development. Where the peoples concerned express a preference for compensation in money or in kind, they shall be so compensated under appropriate guarantees.

5 Persons thus relocated shall be fully compensated for any resulting loss or injury.

\section{Article 17}

1 Procedures established by the peoples concerned for the transmission of land rights among members of these peoples shall be respected.

2 The peoples concerned shall be consulted whenever consideration is being given to their capacity to alienate their lands or otherwise transmit their rights outside their own community.

3 Persons not belonging to these peoples shall be prevented from taking advantage of their customs or of lack of understanding of the laws on the part of their members to secure the ownership, possession or use of land belonging to them. 


\section{Annexes}

Article 18

Adequate penalties shall be established by law for unauthorised intrusion upon, or use of, the lands of the peoples concerned, and governments shall take measures to prevent such offences.

\section{Article 19}

National agrarian programmes shall secure to the peoples concerned treatment equivalent to that accorded to other sectors of the population with regard to:

(a) the provision of more land for these peoples when they have not the area necessary for providing the essentials of a normal existence, or for any possible increase in their numbers;

(b) the provision of the means required to promote the development of the lands which these peoples already possess.

\section{Part III Recruitment and Conditions of Employment}

\section{Article 20}

1 Governments shall, within the framework of national laws and regulations, and in co-operation with the peoples concerned, adopt special measures to ensure the effective protection with regard to recruitment and conditions of employment of workers belonging to these peoples, to the extent that they are not effectively protected by laws applicable to workers in general.

2 Governments shall do everything possible to prevent any discrimination between workers belonging to the peoples concerned and other workers, in particular as regards:

(a) admission to employment, including skilled employment, as well as measures for promotion and advancement;

(b) equal remuneration for work of equal value;

(c) medical and social assistance, occupational safety and health, all social security benefits and any other occupationally related benefits, and housing;

(d) the right of association and freedom for all lawful trade union activities, and the right to conclude collective agreements with employers or employers' organisations.

3 The measures taken shall include measures to ensure:

(a) that workers belonging to the peoples concerned, including seasonal, casual and migrant workers in agricultural and other employment, as well as those employed by labour contractors, enjoy the protection afforded by national law and practice to other such workers in the same sectors, and that they are fully informed of their rights under labour legislation and of the means of redress available to them;

(b) that workers belonging to these peoples are not subjected to working conditions hazardous to their health, in particular through exposure to pesticides or other toxic substances;

(c) that workers belonging to these peoples are not subjected to coercive recruitment systems, including bonded labour and other forms of debt servitude; 
(d) that workers belonging to these peoples enjoy equal opportunities and equal treatment in employment for men and women, and protection from sexual harassment.

4 Particular attention shall be paid to the establishment of adequate labour inspection services in areas where workers belonging to the peoples concerned undertake wage employment, in order to ensure compliance with the provisions of this Part of this Convention.

\section{Part IV Vocational Training, Handicrafts and Rural Industries}

\section{Article 21}

Members of the peoples concerned shall enjoy opportunities at least equal to those of other citizens in respect of vocational training measures.

\section{Article 22}

1 Measures shall be taken to promote the voluntary participation of members of the peoples concerned in vocational training programmes of general application.

2 Whenever existing programmes of vocational training of general application do not meet the special needs of the peoples concerned, governments shall, with the participation of these peoples, ensure the provision of special training programmes and facilities.

3 Any special training programmes shall be based on the economic environment, social and cultural conditions and practical needs of the peoples concerned. Any studies made in this connection shall be carried out in co-operation with these peoples, who shall be consulted on the organisation and operation of such programmes. Where feasible, these peoples shall progressively assume responsibility for the organisation and operation of such special training programmes, if they so decide.

\section{Article 23}

1 Handicrafts, rural and community-based industries, and subsistence economy and traditional activities of the peoples concerned, such as hunting, fishing, trapping and gathering, shall be recognised as important factors in the maintenance of their cultures and in their economic self-reliance and development. Governments shall, with the participation of these people and whenever appropriate, ensure that these activities are strengthened and promoted.

2 Upon the request of the peoples concerned, appropriate technical and financial assistance shall be provided wherever possible, taking into account the traditional technologies and cultural characteristics of these peoples, as well as the importance of sustainable and equitable development.

\section{Part V Social Security and Health}

Article 24

Social security schemes shall be extended progressively to cover the peoples concerned, and applied without discrimination against them. 


\section{Annexes}

Article 25

1 Governments shall ensure that adequate health services are made available to the peoples concerned, or shall provide them with resources to allow them to design and deliver such services under their own responsibility and control, so that they may enjoy the highest attainable standard of physical and mental health.

2 Health services shall, to the extent possible, be community-based. These services shall be planned and administered in co-operation with the peoples concerned and take into account their economic, geographic, social and cultural conditions as well as their traditional preventive care, healing practices and medicines.

3 The health care system shall give preference to the training and employment of local community health workers, and focus on primary health care while maintaining strong links with other levels of health care services.

4 The provision of such health services shall be co-ordinated with other social, economic and cultural measures in the country.

\section{Part VI Education and Means of Communication}

\section{Article 26}

Measures shall be taken to ensure that members of the peoples concerned have the opportunity to acquire education at all levels on at least an equal footing with the rest of the national community.

\section{Article 27}

1 Education programmes and services for the peoples concerned shall be developed and implemented in co-operation with them to address their special needs, and shall incorporate their histories, their knowledge and technologies, their value systems and their further social, economic and cultural aspirations.

2 The competent authority shall ensure the training of members of these peoples and their involvement in the formulation and implementation of education programmes, with a view to the progressive transfer of responsibility for the conduct of these programmes to these peoples as appropriate.

3 In addition, governments shall recognise the right of these peoples to establish their own educational institutions and facilities, provided that such institutions meet minimum standards established by the competent authority in consultation with these peoples. Appropriate resources shall be provided for this purpose.

\section{Article 28}

1 Children belonging to the peoples concerned shall, wherever practicable, be taught to read and write in their own indigenous language or in the language most commonly used by the group to which they belong. When this is not practicable, the competent authorities shall undertake consultations with these peoples with a view to the adoption of measures to achieve this objective.

2 Adequate measures shall be taken to ensure that these peoples have the opportunity to attain fluency in the national language or in one of the official languages of the country. 
3 Measures shall be taken to preserve and promote the development and practice of the indigenous languages of the peoples concerned.

\section{Article 29}

The imparting of general knowledge and skills that will help children belonging to the peoples concerned to participate fully and on an equal footing in their own community and in the national community shall be an aim of education for these peoples.

\section{Article 30}

1 Governments shall adopt measures appropriate to the traditions and cultures of the peoples concerned, to make known to them their rights and duties, especially in regard to labour, economic opportunities, education and health matters, social welfare and their rights deriving from this Convention.

2 If necessary, this shall be done by means of written translations and through the use of mass communications in the languages of these peoples.

\section{Article 31}

Educational measures shall be taken among all sections of the national community, and particularly among those that are in most direct contact with the peoples concerned, with the object of eliminating prejudices that they may harbour in respect of these peoples. To this end, efforts shall be made to ensure that history textbooks and other educational materials provide a fair, accurate and informative portrayal of the societies and cultures of these peoples.

\section{Part VII Contacts and Co-operation across Borders}

\section{Article 32}

Governments shall take appropriate measures, including by means of international agreements, to facilitate contacts and co-operation between indigenous and tribal peoples across borders, including activities in the economic, social, cultural, spiritual and environmental fields.

\section{Part VIII Administration}

\section{Article 33}

1 The governmental authority responsible for the matters covered in this Convention shall ensure that agencies or other appropriate mechanisms exist to administer the programmes affecting the peoples concerned, and shall ensure that they have the means necessary for the proper fulfilment of the functions assigned to them.

2 These programmes shall include:

(a) the planning, co-ordination, execution and evaluation, in co-operation with the peoples concerned, of the measures provided for in this Convention;

(b) the proposing of legislative and other measures to the competent authorities and supervision of the application of the measures taken, in cooperation with the peoples concerned. 


\section{Annexes \\ Part IX General Provisions}

\section{Article 34}

The nature and scope of the measures to be taken to give effect to this Convention shall be determined in a flexible manner, having regard to the conditions characteristic of each country.

\section{Article 35}

The application of the provisions of this Convention shall not adversely affect rights and benefits of the peoples concerned pursuant to other Conventions and Recommendations, international instruments, treaties, or national laws, awards, custom or agreements.

\section{Part $X$ Provisions}

Article 36

This Convention revises the Indigenous and Tribal Populations Convention, 1957.

\section{Article 37}

The formal ratifications of this Convention shall be communicated to the DirectorGeneral of the International Labour Office for registration.

\section{Article 38}

1 This Convention shall be binding only upon those Members of the International Labour Organisation whose ratifications have been registered with the Director-General.

2 It shall come into force twelve months after the date on which the ratifications of two Members have been registered with the Director-General.

3 Thereafter, this Convention shall come into force for any Member twelve months after the date on which its ratification has been registered.

\section{Article 39}

1 A Member which has ratified this Convention may denounce it after the expiration of ten years from the date on which the Convention first comes into force, by an act communicated to the Director-General of the International Labour Office for registration. Such denunciation shall not take effect until one year after the date on which it is registered.

2 Each Member which has ratified this Convention and which does not, within the year following the expiration of the period of ten years mentioned in the preceding paragraph, exercise the right of denunciation provided for in this Article, will be bound for another period of ten years and, thereafter, may denounce this Convention at the expiration of each period of ten years under the terms provided for in this Article. 
Article 40

1 The Director-General of the International Labour Office shall notify all Members of the International Labour Organisation of the registration of all ratifications and denunciations communicated to him by the Members of the Organisation.

2 When notifying the Members of the Organisation of the registration of the second ratification communicated to him, the Director-General shall draw the attention of the Members of the Organisation to the date upon which the Convention will come into force.

\section{Article 41}

The Director-General of the International Labour Office shall communicate to the Secretary-General of the United Nations for registration in accordance with Article 102 of the Charter of the United Nations full particulars of all ratifications and acts of denunciation registered by him in accordance with the provisions of the preceding Articles.

Article 42

At such times as it may consider necessary the Governing Body of the International Labour Office shall present to the General Conference a report on the working of this Convention and shall examine the desirability of placing on the agenda of the Conference the question of its revision in whole or in part.

\section{Article 43}

1 Should the Conference adopt a new Convention revising this Convention in whole or in part, then, unless the new Convention otherwise provides -

(a) the ratification by a Member of the new revising Convention shall ipso jure involve the immediate denunciation of this Convention, notwithstanding the provisions of Article 39 above, if and when the new revising Convention shall have come into force;

(b) as from the date when the new revising Convention comes into force this Convention shall cease to be open to ratification by the Members.

2 This Convention shall in any case remain in force in its actual form and content for those Members which have ratified it but have not ratified the revising Convention.

\section{Article 44}

The English and French versions of the text of this Convention are equally authoritative. 